\title{
Complications of Oral Exposure to Fentanyl Transdermal Delivery System Patches
}

\author{
Jane M. Prosser • Brent E. Jones • Lewis Nelson
}

Published online: 8 June 2010

(C) American College of Medical Toxicology 2010

\begin{abstract}
Purpose Fentanyl is a synthetic opioid available therapeutically as an intravenous, transbucal, or transdermal preparation. It is also used as a drug of abuse through a variety of different methods, including the oral abuse of transdermal fentanyl patches. This is a series of patients with oral fentanyl patch exposure reported to our center and represents the first series of oral fentanyl patch exposures collected outside of the postmortem setting.

Methods In this series, we examined the New York Poison Control Center database for all cases of oral abuse of fentanyl reported between January 2000 and April 2008.

Results Twenty cases were reported, nine were asymptomatic or had symptoms of opioid withdrawal; 11 had symptoms of opioid intoxication. Eight patients were administered naloxone and all showed improvement in clinical status. Only one case resulted in a confirmed
\end{abstract}

J. M. Prosser

Division of Emergency Medicine, Weill Cornell Medical College, New York Presbyterian Hospital,

525 E. 68th St. M130,

New York, NY 10065, USA

e-mail: jprosser100@gmail.com

B. E. Jones $(\bowtie)$

New York University School of Medicine,

New York City Poison Center,

455 First Avenue Suite \#123,

New York, NY 10016, USA

e-mail: brent.e.jones@gmail.com

\section{Nelson}

Department of Emergency Medicine and Fellowship in Medical

Toxicology, New York City Poison Center,

New York University School of Medicine,

455 First Avenue Suite \#123,

New York, NY 10016, USA fatality - this patient had an orally adherent patch discovered at intubation.

Conclusions Oral exposure may result in life-threatening toxicity. Patients should be closely assessed and monitored for the opioid toxidrome, and if symptomatic, should be managed with opioid antagonists and ventilatory support.

Keywords Fentanyl · Transdermal fentanyl - Opioid . Oral abuse

\section{Introduction}

Fentanyl is a synthetic opioid with an analgesic effect that is approximately 100 times more potent than morphine [1]. For therapeutic purposes, it is administered intravenously, transdermally, and transmucosally. Fentanyl was the second most frequent suspect drug in death and serious nonfatal outcomes reported to the FDA's adverse drug event reporting system from 1998 to 2005, suspected in 3,545 deaths [2]. Administration of excessive fentanyl produces the opioid toxidrome, which consists of miosis, depressed level of consciousness, and life-threatening respiratory depression [3].

Use of the transdermal delivery system (TDS) for longterm pain therapy is increasingly popular. In 2007, there were 4.5 million prescriptions for fentanyl patches, an increase of $18.5 \%$ from 2006 [4]. The fentanyl TDS is composed of an adhesive layer, a microporous release membrane or protective layer, a drug reservoir or matrix, and a plastic backing [5]. Fentanyl is contained in the patch as an alcohol-based gel in a hydroxycellulose matrix. Fentanyl is released from the TDS and driven down a concentration gradient into the skin where it forms a depot prior to systemic absorption. Thus, a large amount of 
fentanyl must be contained in each patch to maintain the diffusion gradient. Due to the amount of drug contained in the patch, the high potency of fentanyl, and the psychoactive nature of exogenous opioids, the potential exists for adverse drug events, misuse, and abuse.

Adverse drug effects can occur when the TDS is prescribed to opioid naïve patients, placed over abraded skin, or with the application of heat to the patch [6]. Deaths from the TDS have occurred with both therapeutic application and in the setting of misuse and abuse. Abuse has been reported via a number of different routes, including dermal application of multiple patches, rectal insertion of patches, and intravenous injection or insufflation of the gel [7-10]. Patches can be abused orally by chewing and swallowing the contents or the patch itself. Despite a low oral bioavailability of only $33-50 \%$, toxicity occurs due to the large quantity of fentanyl contained in each patch [11].

This is a series of patients with oral fentanyl patch exposure reported to our center, and represents the first series of oral fentanyl patch exposures collected outside of the postmortem setting.

\section{Methods}

Our poison center database (which contains a record of every call made to the poison center) was searched for calls related to fentanyl patches occurring between January 2000 and April 2008. An Institutional Review Board exemption was granted for the retrospective review of cases. The search terms included "fentanyl," "fentanyl patch," and "Duragesic." Cases that were related to dermal or other routes of toxicity were excluded. The remaining charts were abstracted in a nonblinded fashion by a study investigator (JP) using a standardized data collection instrument that deindentified the data and tabulated the variables of interest. Information was obtained regarding demographics, intent, type and number of patches ingested, clinical findings, therapy, and disposition. Intent was classified in the following manner: abuse was defined as ingestion of fentanyl patches for the purposes of intoxication or the intentional ingestion of a patch prescribed for someone other than the patient. Misuse was defined as ingestion in an attempt to improve pain control by the person who was prescribed the patch for dermal use. Suicidal ingestion was ingestion with intent to terminate one's life.

\section{Results}

We identified 101 cases related to fentanyl patch exposure. The free text fields, which allow poison control center staff to enter more complete case details, of each case were reviewed. Of these, 20 were found to be related to oral fentanyl patch exposure. Nine cases were asymptomatic or had findings related to opioid withdrawal. The remaining 11 cases had findings related to opioid intoxication and are examined in this report.

All of the symptomatic patients with oral exposures occurred in adults, seven of whom were male and four were female. Ten of these 11 cases were hospital calls. All patches were intentionally ingested for reasons of misuse, abuse, or suicide (except one case in which the intent was unknown; see Table 1). The most frequently reported strength was the $100 \mu \mathrm{g} / \mathrm{h}$ patch. One patient was reported by his brother to be "stoned"; he was advised to seek medical care, but was lost to follow-up. One patient's complaints were confined to vomiting. The other nine patients experienced life-threatening complications. All were either unconscious or had inadequate ventilatory effort. All of these nine patients required medical treatment: two required mechanical ventilation; eight received naloxone. All patients who received naloxone responded appropriately with increased respiratory effort or improved mental status.

\section{Discussion}

Two types of fentanyl TDSs are available, reservoir patches that contain the drug in a gel state between layers and matrix patches in which the fentanyl is contained in matrix form [5]. Intact patches can be swallowed, but patches may also be chewed or sliced open before swallowing. Internet searches for "oral fentanyl patch abuse" reveals an extensive number of websites and forums with advice and "directions" for obtaining intoxicating effects from fentanyl containing patches. The websites suggest which brands are considered ideal and different methods of abuse of both reservoir and matrix forms (Table 2). The fentanyl from the original TDS reservoir patch has reportedly been abused by various methods including sucking on the patch, as well as extracting the drug with a needle which is then used for intravenous injection. Alternative methods are used to extract fentanyl from the matrix patches. Some cut patches into dose-appropriate pieces called "Chiclets" and chew the piece like gum [12]. Fentanyl patches have also been used as tea bags to brew fentanyl "tea," which is subsequently ingested or injected [13]. As a result of the abuse potential of opioids coupled with the danger of significant morbidity and mortality of overdose, the FDA has recently announced that risk evaluation and mitigation strategies will be required of the manufacturers of most opioids [14]. One such program is already required of the maker of Onsolis ${ }^{\circledR}$, the fentanyl buccal soluble film [15]. Transdermal applica- 


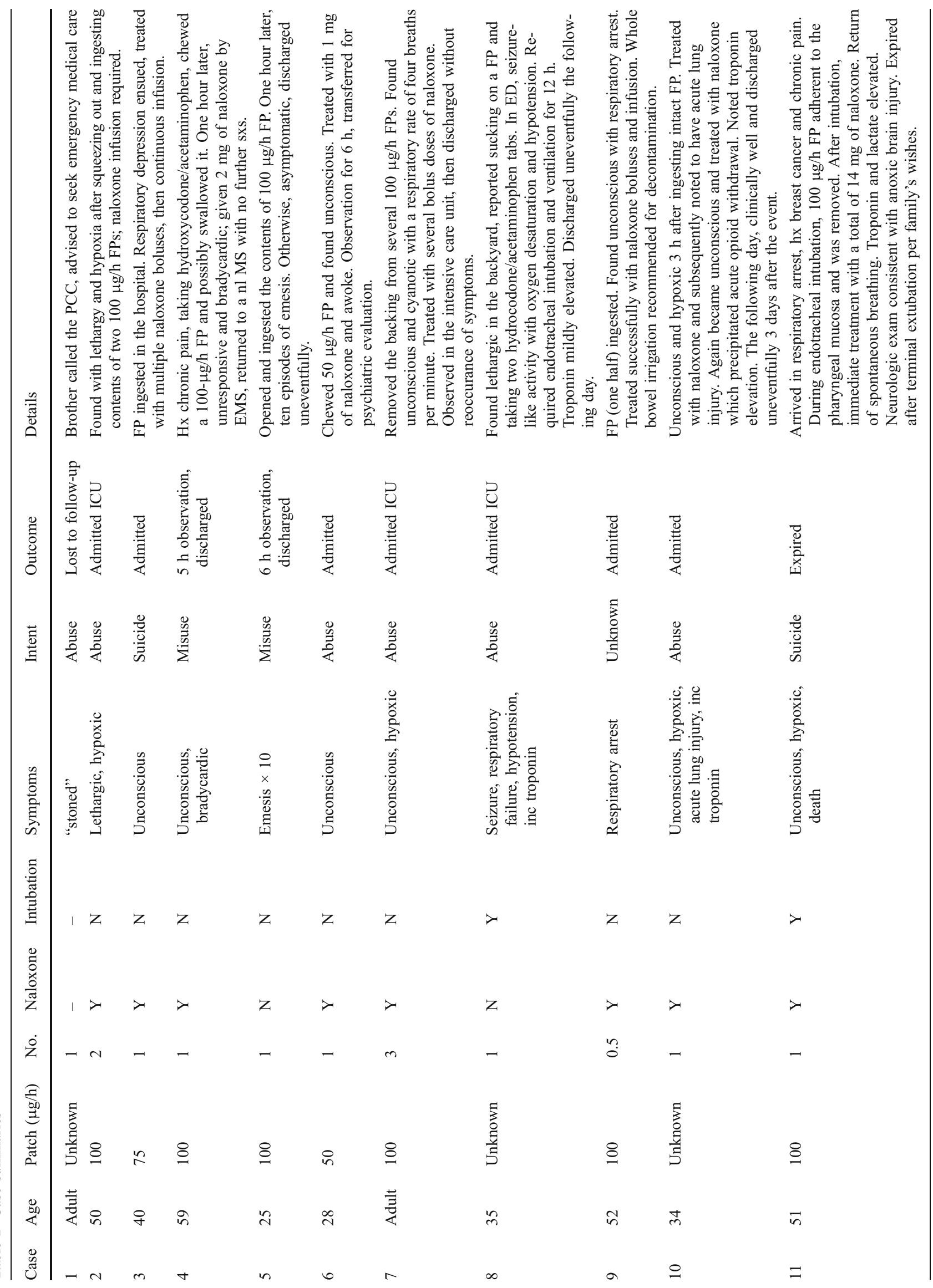


Table 2 Internet instructions on methods of fentanyl abuse

\begin{tabular}{|c|c|}
\hline Method & Instructions \\
\hline Inhalation & $\begin{array}{l}\text { If you want a shorter fentanyl high freebase it off tin foil... Just take about the size of a BB on tin foil. Fold the tin foil into } 4 \\
\text { squares and when the } 2 \text { fold cross put the fentanyl there so you won't lose it since it kind of goes invisible. Then take a empty } \\
\text { pen cap and hold it close very close and start hitting the second you hear the sizzle. }\end{array}$ \\
\hline Injection & $\begin{array}{l}\text { You can cut a hole in it like somebody said and squirt the gel in to spoon. I suggest just snipping off the corner with the backing } \\
\text { on still. add vinegar (or similar acid). cook it. draw up no cotton or anything, use one of the rigs that has a removable point. I } \\
\text { suggest adding some saline to weaken the mixture because it can burn otherwise and still might. The high this way is awesome. }\end{array}$ \\
\hline Transdermal & $\begin{array}{l}\text { Scratch and abrade your skin before applying the (Mylan) patch... Apply heat, as hot as you can tolerate... such as by a)sitting in a } \\
\text { hot tub, b)applying a heating pad, c) blowing a hair dryer directly on the patch or c) get creative! Just don't burn yourself. }\end{array}$ \\
\hline Oral & $\begin{array}{l}\text { I hate the duragesic brand the generics by mylan are better in everyway... With the mylans you can cut a } 10 \text {-mg patch into four } \\
\text { quarters, eighths or more... Then chew on the plastic for a half hour or so... (the Mylan patch is) much easier to measure and } \\
\text { keep for oral use. The duragesics suck... if you want to cut it open you have to try to even out the gel, once cut you have to store } \\
\text { it very carefully not to ruin it. Just a pain... compared to the generics. }{ }^{\text {. }}\end{array}$ \\
\hline Multiple & $\begin{array}{l}\text { There are so many ways to abuse the (Duragesic) gel it's almost funny. The nasal spray works... smoking the gel works quite well, } \\
\text { and you can even rub the gel in your eyes... Orally, use a Q-tip to swab it on your gums or suck on a piece of gauze saturated } \\
\text { with gel. Do not swallow... }\end{array}$ \\
\hline
\end{tabular}

${ }^{a}$ Re: Fentanyl Patches: Shootable? 2005. http://forum.opiophile.org/archive/index.php/t-299.html. Accessed 2 Nov 2009

${ }^{\mathrm{b}}$ Re: Fentanyl Patches: Shootable? 2005. http://forum.opiophile.org/archive/index.php/t-299.html. Accessed 2 Nov 2009

c The Eagle's Fentanyl Patch Guide. 2009. http://www.bluelight.ru/vb/showthread.php?t=424365. Accessed 2 Nov 2009

${ }^{\mathrm{d}}$ The Mylans are better than Duragesic.2006. http://www.drugs-forum.com/forum/showthread.php?t=13456. Accessed 2 Nov 2009

e The Eagle's Fentanyl Patch Guide. 2009. http://www.bluelight.ru/vb/showthread.php?t=424365. Accessed 2 Nov 2009

tion of fentanyl patches results in a slowly absorbed bioavailability of approximately $92 \%$. Oral exposure fentanyl results in a lower bioavailability ranging from $33 \%$ to $50 \%$, depending on the site of absorption, but is more rapid in nature [16]. Patches $(75 \mu \mathrm{g})$ placed in simulated gastric and intestinal fluid were found to begin releasing within $5 \mathrm{~min}$ and at $3 \mathrm{~h}$ had released an average of 26 and $41 \%$ of the drug, respectively [17].

Following administration of a fentanyl lozenge, approximately $25 \%$ of the total dose is rapidly absorbed across the buccal mucosa. The remaining $75 \%$ of the dose is swallowed, of which approximately one third (or 25\% of the original total dose) becomes systemically available after first pass elimination [16]. Thus, the expected systemic dose will vary if the fentanyl patch is sucked, chewed, and swallowed intact. Despite this relatively low oral bioavailability compared to transdermal application, life-threatening toxicity can result from ingestion of fentanyl patches.

A typical dose of intravenous fentanyl is $100 \mu \mathrm{g}$, and the dose in the lozenge is $200 \mu \mathrm{g}$. Thus, the amount contained in each patch is orders of magnitude larger than the usual recommended dose (Table 3). Even after 3 days of use as recommended by the manufacturer, significant amounts of drug, up to $84 \%$ in one study, can remain in the patch [18]. Toxicity, including death, has been reported from ingestion of used patches [19].

Previous reports of oral patch exposures have been limited to case reports and postmortem case series. One series of seven patients using medical examiner data revealed seven deaths over a 3-year period attributed to oral patch exposure. Except in one case of unknown manner of death, all were attributed to "accidental" overdose [20].

Similar to patient no. 11 in this series, three patients with orally adherent patches are reported and all expired [2022]. Each of these patients had high postmortem drug concentrations ranging from 17 to $32 \mathrm{ng} / \mathrm{mL}$ (therapeutic range approximately $0.7-3 \mathrm{ng} / \mathrm{mL}$ ) [23]. It is unclear if these patients' deaths resulted from mechanical airway obstruction, transmucosal absorption, or some combination of both. Clinicians caring for patients with a history of patch use and an opioid toxidrome should inspect the oropharynx.

This report highlights the utility of mechanical ventilation and naloxone for management of patients with lifethreatening respiratory failure due to patch ingestion. All nine patients with respiratory compromise responded to either naloxone or ventilation. Additionally, all eight patients who were administered naloxone responded appropriately

Table 3 Total amount of fentanyl contained in fentanyl patches

\begin{tabular}{ll}
\hline Strength $(\mu \mathrm{g} / \mathrm{h})$ & Total fentanyl $(\mu \mathrm{g})$ \\
\hline 12.5 & 1,250 \\
25 & 2,500 \\
50 & 5,000 \\
75 & 7,500 \\
100 & 10,000 \\
\hline
\end{tabular}


with an improvement in clinical status. Naloxone is an opioid antagonist with an elimination half-life of $60-90 \mathrm{~min}$ [24]. Patients treated with naloxone must be monitored closely and consideration should be given to a continuous infusion if opioid toxicity recurs.

\section{Limitations}

This study has several limitations related to use of a poison center database. Calls to the poison center are voluntary on the part of patients and medical practitioners. Thus, reporting bias is likely and there can be no estimation of prevalence. The data was collected as part of routine poison control center calls and then retrospectively reviewed. There was no standardized form used with questions specific to fentanyl. Therefore, some information of interest such as the doses of naloxone administered were not always gathered. Additionally, confirmation of ingestion was not obtained with serum fentanyl concentrations. While this information would have strengthened the study, fentanyl concentrations are not routinely obtained during clinical care as they are not available in a useful timeframe. Additionally, all patients had a history and clinical findings consistent with opioid exposure, and all who were treated with naloxone responded strongly corroborating fentanyl patch ingestion.

\section{Conclusion}

This series highlights the dangers of ingestion of fentanyl patches. Oral exposure may result in life-threatening toxicity. Patients should be closely assessed and monitored for the opioid toxidrome, and if symptomatic, should be managed with opioid antagonists and ventilatory support.

\section{References}

1. Mather LE (1983) Clinical pharmacokinetics of fentanyl and its newer derivatives. Clin Pharmacokinet 8:422-446

2. Moore TJ, Cohen MR, Furberg CD (2007) Serious adverse drug events reported to the food and drug administration, 1998-2005. Arch Intern Med 167:1752-1758

3. Nelson LS (2006) Opioids. In: Goldfrank's Toxicologic Emergencies. 8th (ed.) New York: McGraw-Hill, pp 540-613
4. http://drugtopics.modernmedicine.com/Pharmacy+Facts +\& +Figures. Last accessed 03/28/08.

5. Nelson LS, Schwaner R (2009) Transdermal fentanyl: pharmacology and toxicology. J Med Toxicol 5:230-241

6. Janssen Pharmaceutical. Duragesic ${ }^{\mathbb{B}}$ approved package insert. Titusville, NJ. Available from: http://www.duragesic.com/ duragesic/shared/pi/duragesic.pdf. Last accessed 06/06/2009.

7. Anderson DT, Muto JJ (2000) Duragesic transdermal patch: postmortem tissue distribution of fentanyl in 25 cases. J Anal Toxicol 24:627-634

8. Coon TP, Miller M, Kaylor D, Jones-Spangle K (2005) Rectal Insertion of fentanyl patches: a new route of toxicity. Ann Emerg Med 45:473

9. Tharp AM, Winecker RE, Winston DC (2004) Fatal intravenous fentanyl abuse: four cases involving extraction of fentanyl from transdermal patches. Am J Forensic Med Pathol 25:178-181

10. Marquardt KA, Tharratt RS (1994) Inhalation abuse of fentanyl patch. Clin Toxicol 32:75-78

11. Streisand JB, Varvel JR, Stanski DR et al (1991) Absorption and bioavailability of oral transmucosal fentanyl citrate. Anesthesiology 75:223-229

12. Jentzen JM. Alternative drug-delivery systems are subject to abuse. In: Clinical and Forensic Toxicology News. http://www.aacc.org/ publications/toxicology/Documents/9023f590e32540b29c02cf 27a1320efedec03.pdf. Last accessed 09/01/2009.

13. Barrueto F Jr, Howland MA, Hoffman RS (2004) The fentanyl tea bag. Vet Human Toxicol 46:30-31

14. http://www.fda.gov/Drugs/DrugSafety/InformationbyDrugClass/ ucm163647.htm. Last accessed 10/20/2009.

15. http://www.fda.gov/Drugs/DrugSafety/PostmarketDrugSafety InformationforPatientsandProviders/ucm 172039.htm. Last accessed 10/20/2009.

16. Varvel JR, Shafer SL, Hwang SS et al (1989) Absorbtion characteristics of transdermally administered fentanyl. Anesthesiology 70:928-934

17. Arroyo AM, Smith J, Kriger S, Mowry J (2009) In-vitro release of fentanyl from transdermal patches in gastric and intestinal fluid. Clin Toxicol 47:706

18. Hardwick WE, King WD, Palmisano PA (1997) Respiratory depression in a child unintentionally exposed to transdermal fentanyl patch. South Med J 90:962-964

19. Marquardt KA, Tharratt RS, Musallam NA (1995) Fentanyl remaining in a transdermal system following three days of continuous use. Ann Pharmacother 29:969-971

20. Woodall KL, Martin TL, McLellan BA (2008) Oral abuse of fentanyl patches (Duragesic): seven case reports. J Forensic Sci 53:222-225

21. Kuhlman JJ, McCaulley R, Valouch TJ, Behonick GS (2003) Fentanyl use, misuse, and abuse: a summary of 23 postmortem cases. J Anal Toxicol 27:499-504

22. Kramer C, Tawney M (1998) A fatal overdose of transdermally administered fentanyl. J Am Osteo Assoc 98:385

23. Grond S, Radbruch L, Lehmann KA (2000) Clinical pharmacokinetics of transdermal opioids: focus on transdermal fentanyl. Clin Pharmacokinet 38:59-89

24. Howland MA (2006) Antidotes in depth: naloxone. In Goldfrank's Toxicologic Emergencies 8th (ed.) New York: McGraw-Hill. pp 540-613 